\title{
Multifunctional platform OPI-TPP for post- mining areas management - supportive tool for environmental impact assessment in the Silesia Voivodeship
}

\author{
Jan Bondaruk* , Adam Hamerla , and Karolina Jąderko-Skubis \\ Central Mining Institute, plac Gwarków 1, Katowice, Poland
}

\begin{abstract}
Ongoing transformation of coal industry taking place in Silesian Voivodeship lead to increasing number of characteristic objects and post-industrial areas. Most of them are degraded and vacant even if they own resources of measurable natural or socio-economic value. Therefore effective scheme of their revitalisation is a high priority target for regional authorities and society.

Multidimensional approach to the analysis of post-mining areas requires ensuring proper scope and quality of data, integrating various areas of knowledge and information. An example of complex approach is an information platform based on analytical and expert modules - the OPITPP system, which is a tool to support decision-making processes on the future use of post-industrial areas.

OPI-TPP based on Geographical Information System is an integrated tool dedicated for environmental impact assessment and provides measures that are necessary for regional and local stakeholders and reinforces decision making process.

This paper describes the methodology of post-mining area assessment in environmental impact aspect and exemplary applications with the use of the platform. The main functional relations of the system were presented, allowing to use the available range of data and analysis modules for the purpose of supporting environmental impact assessment for post-mining areas management in the Silesia Voivodeship.
\end{abstract}

\section{Introduction}

In recent years, there has been an intensive development of information and support systems, which accompany the activities of many areas of economic activity and public administration.

The use of IT systems in chosen management processes allows to improve these processes, increase their effectiveness as well as to improve the implementation of complex operations that require a multidimensional approach to the analysed issue.

\footnotetext{
* Corresponding author: jbondaruk@gig.eu
} 
The digitalization of resources and services leads to a paradigm shift in the planning, implementation and monitoring of development processes. The integration of data and the availability of data analysis tools determine the development of complex decision support systems. Therefore, in response to the need to develop a modern IT system integrating various areas of knowledge and information on post-industrial and degraded areas in relation to the defined elements of the environment in the Silesian Voivodeship, the OPITPP system has been developed.

The OPI-TPP system (Generally Accessible Information Platform - Postindustrial Areas) is a tool enabling the introduction, collection, processing, verification and updating of data and information on post-industrial areas and objects in accordance with the implemented policy of information society, with particular emphasis on access to information on the environment [1]. The OPI-TPP system, as a complete and integrated platform (Fig.1), is an element of the RSIP (regional spatial information system) and national Spatial Information Infrastructure, thus providing an opportunity not only to present selected data or information but also to use them in multi-criteria analyses, including environmental risk analysis or preferred direction of land reclamation. In the context of environmental analyses, the OPI-TPP system is, first of all, a tool providing:

- comprehensive and aggregated information on the current state of the environment,

- identification of environmental conflicts and assessment of environmental impact together with classification of the area presenting risk in the analysed context,

- effective use of environmental data collected within the project and made available by their administrators, environmental protection institutions and other institutions obliged to keep data registers and their graphic presentation.

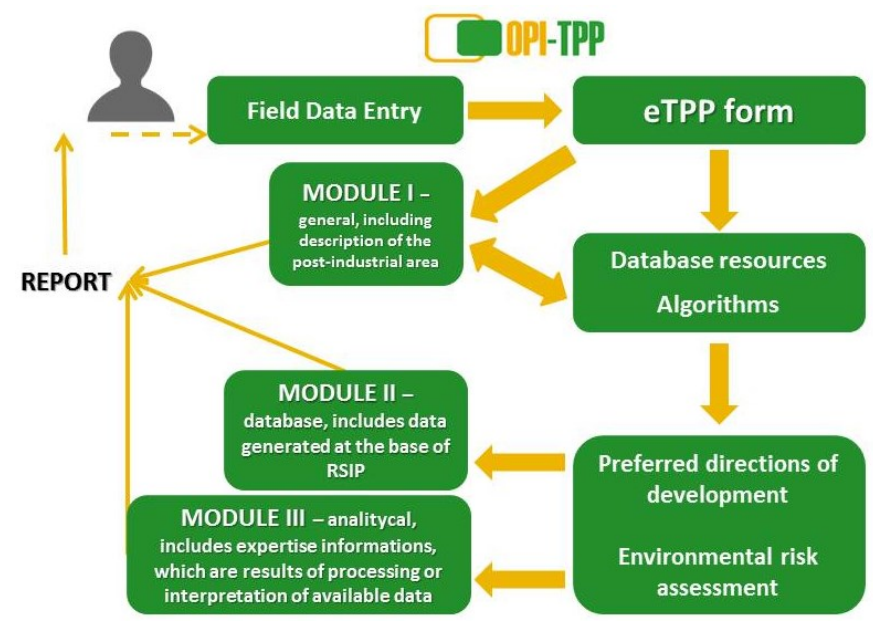

Fig. 1. The architecture of OPI-TPP (based on [2])

Wide access to data and multi-level approach to data processing allows OPI-TPP system users to effectively plan and operate in the area of spatial management embrace post-industrial and industrial areas, urban development, environmental protection and economic activity.

\section{Systems supporting environmental analysis and assessment with the use of spatial data - examples of applications}


The idea of using support systems as well as their functional capabilities have caused that for many years research has been carried out on adapting systems to various types of processes, areas of intervention and the broad scope of decisions to be made. Although GIS technologies find practical application in many areas, their use can be extended and improved by creating spatial decision support systems (SDSS) adapted to individual requirements. A general scheme of the SDSS architecture is presented in Figure 2.

The literature contains many examples of systems that provide and integrate a wide range of data and information depending on the context and current user needs. This is due, inter alia, to the current EU approach $[3,4,5]$ to speeding up the digital transition in administration. The EU eGovernment Action Plan 2016-2020 [5] highlights the importance of innovation in the development of applications in the area of spatial data use in urban planning, spatial planning and traffic planning in order to directly reduce the negative impact on the environment. Another reason for the growing interest in digital services related to data processing are the individual needs of the region, which determine the subject of implementation and identify conditional factors.

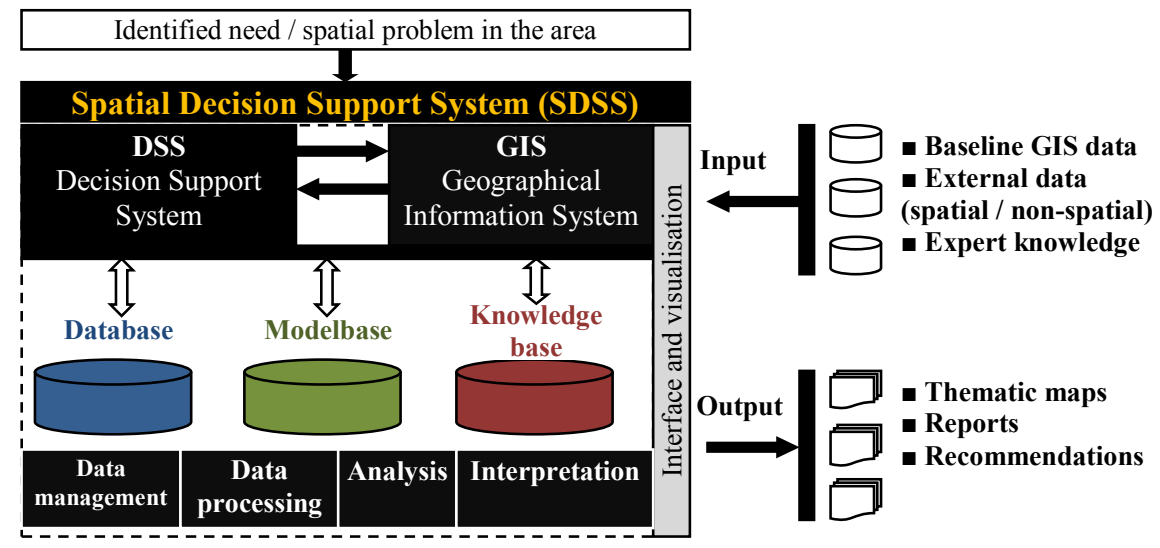

Fig. 2. Scheme of data exchanged within the SDSS

In addition, the possibilities of integrating multi-criteria decision analysis tools (MCDA) and GIS tools make it recommended to use and achieve interoperability during the decision-making process in order to solve a specific environmental problem, but also in the practice of urban management. Examples of GIS-based multi-criteria analysis implementations are used worldwide.

The paper [6] attempts to establish a spatial decision support system for newly reclaimed areas, characterized especially by saline soils in dry regions (the research area is located on the El-Tina plain in the north-western part of the Sinai Peninsula). The aim of the work on SDSS tool development was to build a database and elaborate models that will support the provision of an appropriate land use plan for the studied area.

In the publication [7], the authors propose to use the spatial decision support system based on the Geographical Information System (GIS) to assess the environmental aspects of construction. The system is designed to assist urban planners and consultants in decision making in the field of sustainable urban development strategy implementation. The system presents a unique methodology of implementing a building multi-criteria environmental impact assessment (based on the international scoring system of the SbTool) within the framework of GIS, which is the main architectural element of the whole system.

Another example of supporting urban space management by a decision support system based on GIS is DESYRE (Decision Support sYstem for the REqualification of contaminated sites), which aims at supporting and solving the issue of integrated management and choosing the direction of remediation of contaminated areas [8]. 
DESYRE DSS supports decision-makers during the remediation process, as part of an integrated and comprehensive environmental problem analysis based on a multi-criteria approach. As a result, based on a risk analysis, the user receives a set of remediation scenarios developed by the Expert and containing, among other things, the total cost of the process and the time needed to carry it out.

As it has already been proved and discussed above, the literature presents a wide and varied spectrum of functionalities and implementations of systems based on spatial data [9]. Thus, also in the context of the Polish economy and administration many implementations of systems can be observed, such as:

- IKAR - Integrated Geological Cartography System - the effect of the Polish Geological Institute project, which includes standardization and harmonisation of spatial geological data and enabling their use through interoperable online geoinformation services [10].

- A system supporting the revitalisation of coal mining waste dumps with the use of geoinformatic tools - a project which has developed a method enabling optimisation of decisions concerning the reclamation and management of coal mining waste dumps, based on a elaborated mathematical model [11].

- REVITAL - innovations in revitalization of degraded areas in Podkarpackie Voivodeship - the aim of the project was to develop a database of post-industrial areas in Podkarpackie Voivodeship [9].

In response to local needs, systems dedicated to identified problem areas are also implemented. Such an example is the ROPSIM (Registration of Polluted Sites in Malopolskie Voivodeship) database, which is a result of inventory work on contaminated or potentially contaminated sites in the Małopolskie Voivodeship [12]. The basic database contains 845 objects, which allowed for the development of an effective tool for monitoring the condition of ecological safety and for corrective actions decisions making.

In the Silesian Voivodeship, a specific region of Poland due to the degree of industrialization and urbanization, in 2010 the development of the Open Regional Spatial Information System (ORSIP) was started, within which a thematic subsystem was implemented the abovementioned OPI-TPP system [1].

\section{Environmental impact assessment in OPI-TPP}

The OPI-TPP platform was developed in 2013 as a tool to support the process of reconversion of post-industrial areas, including postmining areas in the Silesian Voivodship - one of the most extensive areas of hard coal mining in Europe. It is an IT tool fully integrated with the regional spatial information system (RSIP), allowing for effective implementation of the policy of restoring post-mining areas to the social and economic circulation. Within the framework of the inventory, over 1000 post-industrial areas were catalogued, of which over $30 \%$ is related to the mining activities of the coal sector.

The platform developed and disseminated supports mainly in the field of the assessment of environmental changes caused by industrial activity, the scale of environmental risk and, on the basis of identified external factors, the preferred directions of reuse of these areas in the form of reconversion scenarios. 
The platform identified 49 types of business activities on the basis of which the actual and potential impact on the quality of the natural environment is assessed. Following 10 categories are directly related to mining activities: (1) area after a closed mine or a mine shaft (coal or ore mining), (2) heap from hard coal mining, (3) heap from ore mining, (4) post-flotation ore heap, (5) dump for post-energy waste, (6) water tank levelled with compacted inert material, (7) an excavation or settling tank filled with municipal waste, (8) wetlands caused by hard coal or ore mining activities without buildings, (9) wetland caused by hard coal activities with buildings, (10) dispersed areas, permanently threatened by discontinuous deformations due to former shallow mining exploitation.

In practice, post-industrial areas are repeatedly used for various activities, leading to the accumulation of negative impacts on the environment and making it more difficult to identify the scale of potential hazard.

Other indicators resulting from the nature of the activity and taken into account in the environmental impact assessment are spatial parameters such as the size of the area, its exposure or morphological diversity, existing buildings and their condition, waste accumulated in the area.

External indicators take into account in the environmental risk assessment include hydrological and hydrogeological conditions, soil types, location in relation to green areas or naturally valuable areas. The algorithm according to which the impact of the conducted activity on the environment is assessed includes the following external elements independent of the genesis of the activity conducted in historical times:

- sensitivity of the soil to external impacts (erosion) - the type of soil, the slope of the terrain, the risk of flooding, altitude above sea level.

- Sensitivity of groundwater to pollution - time at which pollutants reach the first aquifer.

- Sensitivity of surface water to pollution - distance from sewage treatment plants at risk of flooding, distance from a landfill site at risk of flooding, current land use.

- Analysis of exposure to noise and vibration - the distances from: the railway line, national road and highway, the tram line, the airport, the open - air auditorium, the city centre.

- Impact on protected areas - the distances from: the national park, another protected object, the NATURA2000 site.

The assessment of environmental effects is based on a specially developed algorithm that aim at to find out the direct impact on the process of reconversion of the post-industrial area. The evaluation tool based on the algorithm uses information gathered in a regional database dedicated to post-industrial areas. The collected information is coupled with environmental and spatial data collected in other databases integrated within the regional spatial information system.

Environmental assessment algorithm being developed and implemented within the system enabling in particular the analysis of environmental risk, classifies areas based on the information contained in Module I and in spatial analysis data. The risk analysis within environmental impact assessment of contaminated areas is a process that depends on many factors. The assessment algorithm is structured around criteria based on the following groups of elements: (1) characterisation of the contaminant, (2) characterisation of the contaminant pathway in the environment, (3) type of contaminant receiver (receptor). The maximum assessment value is 100 points, which means that each of the three groups can give a maximum of 33-34 points in the overall assessment (equal impact of the individual components on the final assessment). The result of the analysis expressed in numerical values is an assessment of environmental risk, together with its categorisation (high, medium, moderate, low) and determination of the need to take protective and remediation actions. The outcome of an exemplary analysis together with the classification of environmental risk are presented in the Fig 3. 
The assessment allows to determine the degree of risk for the environment related to the lack of remedial actions. As a result, it makes it possible to rank the needs and directions of disposing of appropriate financial and organisational resources.

The final result of the analysis is the evaluation of the area in terms of the risk it causes for the environment. Giving a numerical value to the phenomenon enables the hierarchy of significance of undertaken actions and supports the process of managing the revitalisation process in a comprehensive way. In this perspective the platform can be used to support the definition of priority actions in the transformed areas.

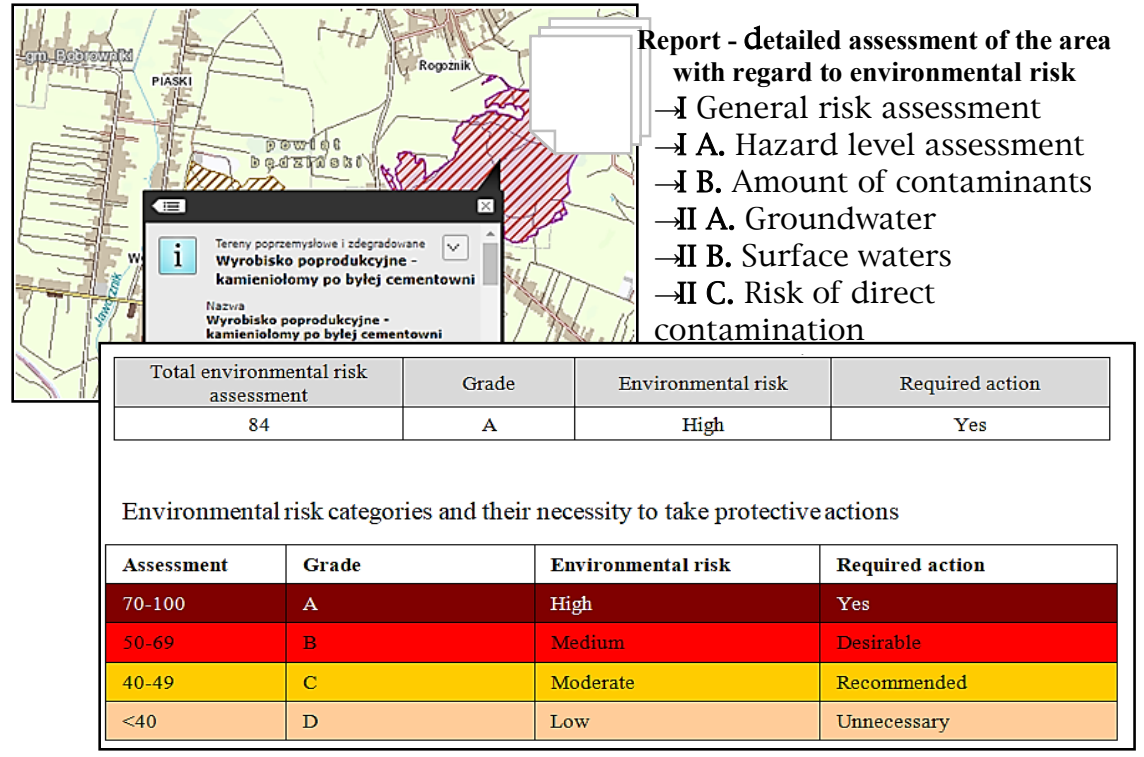

Fig. 3. Report elements for exemplary area analysis - post-production excavation - former cement works quarries (based on [2])

At the same time, the platform analyses the attractiveness of the post-industrial area in terms of its reuse for economic circulation. On the basis of this assessment, a future form of development of the post-industrial area is suggested. Moreover the OPI-TPP information platform enables the user to conduct own analyses on the basis of modified input values or to change the values of weights adopted for particular factors by the authors of the algorithm. This causes the users to have full access to the system and its database, also including possibility of comparing data.

\section{CONCLUSIONS}

Components determined on the basis of the results of analyses derived from the calculation modules of the OPI-TPP platform, constitute the basis for the selection of the most probable scenario for the development of a post-industrial area, including post-mining areas. The tool was used, among others, in the elaboration of a reconversion plan for a closed Krupiński mining site, in Suszec, in the Upper Silesian Coal Basin. With the support of the system, three alternative scenarios for future land-use planning were developed: energy, logistics and cultural. The system is also used in international initiatives for revitalisation projects. It supported, among others, the implementation of the Interreg Central Europe project, under which a zinc waste dump in Ruda Slacksa, one of the most industrialised cities in Poland, was successfully revitalized. Determination of the scenario and the direction of activities may be the basis for undertaking detailed analyses aimed at 
determining the possibilities of its implementation, including investment costs. The analysis and evaluation of the areas, including the ecological criterion, allows to specify the methodology of management of the areas whose characteristics are stored in the system database - in terms of their valorisation due to the ecological impact. This means that the areas qualified for the database are subject to further evaluation in order to make them prioritised. This prioritisation shall be carried out on the basis of the degree of risk that the areas cause to the environment and/or human health in the region. Prioritisation is necessary for proper decision making on the issue of the expenses to prevent further risks from industrial sites.

Within the framework of the valorization, the areas which are characterized by the following arguments are highlighted:

- there is a guarantee, on the basis of the conducted research, that they pose a risk to the environment and/or human health,

- the risk hypothesis must be confirmed or excluded by carrying out research,

- reclamation activities must be taken whose scope and method are determined by environmental conditions in each individual case. After reclamation, the area may be transformed to acquire some new functions including ecosystem services.

\section{References}

1. J. Bondaruk, P. Zawartka, Public Information Platform "Post-industrial and degraded areas" (OPI TPP) - modern tool for information management system regarding postindustrial areas in Silesia Voivodeship, Research Reports Mining And Environment, 4/2011, pp.31-49 (2011)

2. Project description. Available on https://www.orsip.pl/web/opitpp

3. European Commission, Communication from the Commission to the European Parliament, the Council, the European Economic and Social Committee and the Committee of the Regions: Towards a thriving data-driven economy, COM/2014/0442 final (2014)

4. European Commission, Communication from the Commission to the European Parliament, the Council, the European Economic and Social Committee and the Committee of the Regions: Open data - An engine for innovation, growth and transparent governance $\operatorname{COM}(2011) 882(2011)$

5. European Commission, Communication from the Commission to the European Parliament, the Council, the European Economic and Social Committee and the Committee of the Regions: EU eGovernment Action Plan 2016-2020. Accelerating the digital transformation of government, $\operatorname{COM}(2016) 179$ final (2016)

6. Th.K.Ghaboura, R.R.Alia, M.M.Wahbaa, E.A.El-Nakab, S.A.Selima, Spatial decision support system for land use management of newly reclaimed areas in arid regions, The Egyptian Journal of Remote Sensing and Space Science. Available on https://www.sciencedirect.com/science/article/pii/S1110982317303502

7. M.C. Ruiz Puente, I. Fernández Diego, Environmental Assessment in construction using a Spatial Decision Support System, Automation in Construction, 18(8), pp. 1135-1143 (2009)

8. C. Carlon, A.Critto, E.Ramieri, A. Marcomini, DESYRE: Decision support system for the rehabilitation of contaminated megasites, Integrated Environmental Assessment and Management, Vol. 3, Number 2, pp. 211-222 (2006)

9. E. Zagórska, Provincial databases on degraded post-industrial and post-military areas as an element supporting their transformation processes in line with the principles of sustainable development (published in Polish), Journal of Management and Finance, Vol. 12, No. 4/2014, pp. 553-564 (2014)

10. IKAR project description.

Available

on http://www.gispartner.pl/wdrozenia/srodowiskowe/03.html

11. Project description. Available on http://www.transfer.us.edu.pl/system-wspomaganiarewitalizacji-zwalowisk-odpadow-pogorniczych-przy-uzyciu-narzedzi-geoinformatyczn 
12. R. Uberman, W. Naworyta, Assessment of state and needs of land reclamation and revitalization of post mining aeas in Małopolska Voivodeship, Górnictwo i Geoinżynieria, Rok 29, Zeszyt 4, pp. 207-2017 (2005)

13. González, GIS in Environmental Assessment: A Review of Current Issues and Future Needs. Journal of Environmental Assessment Policy and Management, Vol. 14, No. 1 (2012)

14. K.Gharehbaghi, Ch. Scott-Young, GIS as a vital tool for Environmental Impact Assessment and Mitigation, IOP Conf. Series: Earth and Environmental Science, Vol. 127 (2018) 